\title{
Deep frontal and periventricular age related white matter changes but not basal ganglia and infratentorial hyperintensities are associated with falls: cross sectional results from the LADIS study
}

\author{
C Blahak, ${ }^{1}$ H Baezner, ${ }^{1}$ L Pantoni, ${ }^{2}$ A Poggesi, ${ }^{2}$ H Chabriat, ${ }^{3}$ T Erkinjuntti, ${ }^{4}$ F Fazekas, ${ }^{5}$ \\ J M Ferro, ${ }^{6}$ P Langhorne, ${ }^{7} \mathrm{~J}$ O'Brien, ${ }^{8} \mathrm{M} \mathrm{C}$ Visser, ${ }^{9} \mathrm{~L}-0$ Wahlund, ${ }^{10} \mathrm{G}$ Waldemar, ${ }^{11}$ \\ A Wallin, ${ }^{12} \mathrm{D}$ Inzitari, ${ }^{2} \mathrm{M}$ G Hennerici, ${ }^{1}$ on behalf of the LADIS Study Group
}

- A list of participating centres and personnel is published online only at http://jnnp.bmj. com/content/vol80/issue6

${ }^{1}$ Department of Neurology, University of Heidelberg, Klinikum Mannheim, Mannheim, Germany; ${ }^{2}$ Department of Neurological and Psychiatric Sciences, University of Florence, Italy: ${ }^{3}$ Department of Neurology, Hôpital Lariboisiere, Paris, France: ${ }^{4}$ Memory Research Unit, Department of Clinical Neurosciences, Helsinki University, Helsinki, Finland;

${ }^{5}$ Department of Neurology and MRI Institute, Medical University Graz, Austria; ${ }^{6}$ Serviço de Neurologia, Centro de Estudos Egas Moniz, Hospital de Santa Maria Lisboa, Portugal;

${ }_{7}^{7}$ Academic Department for Geriatric Medicine, Glasgow Royal Infirmary, Glasgow, UK;

${ }^{8}$ Institute for Ageing and Health, University of Newcastle,

Newcastle upon Tyne, UK;

${ }^{9}$ Departments of Radiology and Neurology, VU Medical Centre, Amsterdam, The Netherlands;

${ }^{10}$ Karolinska Institute,

Department of Clinical

Neuroscience and Family

Medicine, Huddinge, University

Hospital, Huddinge, Sweden;

${ }^{11}$ Memory Disorders Research

Unit, Department of Neurology,

Copenhagen University Hospital,

Copenhagen, Denmark;

${ }^{12}$ Institute of Clinical

Neuroscience, Goteborg

University, Goteborg, Sweden

Correspondence to:

Dr C Blahak, Department of Neurology, Universitätsklinikum

Mannheim, Theodor-Kutzer Ufer

1-3, D-68167 Mannheim,

Germany; c.blahak@

neuro.ma.uni-heidelberg.de

Received 7 July 2008

Revised 6 November 2008

Accepted 3 December 2008

Published Online First

9 February 2009

\section{ABSTRACT}

Background: Global age related white matter changes (ARWMC) are associated with progressive gait disturbances and falls, hypothesised to result from interruptions of cortico-subcortical circuits controlling balance, posture and locomotion.

Methods: The location of ARWMC in a large cohort of elderly non-disabled individuals with reported falls was analysed, using the cross sectional data of the Leukoaraiosis and Disability (LADIS) study. Detailed anatomical distributions of ARWMC assessed by MRI studies were analysed with respect to falls and balance performance.

Results: The severity of global ARWMC was significantly associated with a history of falls in the year prior to study inclusion $22.2 \%$ in the mild, $31.6 \%$ in the moderate and $37.3 \%$ in the severe ARWMC group according to the Fazekas scale; $p=0.002$ ). Analysing the anatomical distribution of ARWMC, using the semiquantitative Scheltens scale, in multivariate analysis, periventricular ( $p=0.006)$ and frontal deep ( $p=0.033$ ) ARWMC were independently associated with falls. Furthermore, logistic regression identified frontal deep ( $p=0.003)$ ARWMC, but not basal ganglia and infratentorial hyperintensities, as significantly associated with balance disturbances.

Conclusion: The association of frontal and periventricular ARWMC with falls supports the hypothesis that interruption of frontal subcortical motor circuits lead to balance disturbances and hence to an increased risk for falls in ARWMC.

Changes in the cerebral white matter, also called leukoaraiosis, ${ }^{1}$ are detected frequently on brain imaging of elderly persons and are known to be associated with several vascular risk factors. ${ }^{1-4}$ Apart from hypertension, age is one of the most important factors linked with leukoaraiosis and therefore the term age related white matter changes (ARWMC) has been introduced to define these structural alterations ${ }^{5}$ and to separate them from other diseases of the white matter observed in younger patients. ${ }^{6}$

One of the key clinical features associated with ARWMC are motor abnormalities such as gait ${ }^{7-10}$ and balance impairment, ${ }^{10}{ }^{11}$ which lead to considerable medical and socioeconomic problems. Recurrent falls are associated with physical decline and disability, resulting in psychosocial problems and a significant reduction in quality of life. ${ }^{12}$ In addition, falls are correlated with an increased injury related mortality ${ }^{13}$ and notable medical expenses due to hospitalisation caused by fall related injuries. ${ }^{12} 14$

Various risk factors for falls have been proposed, among them visual impairment, functional limitations in daily living, an abnormal postural sway and an increased gait and stride variability. ${ }^{12} 1516$ Several neurodegenerative disorders, such as Parkinson's disease, ${ }^{17}$ Alzheimer's dementia and various conditions associated with cerebellar ataxia, ${ }^{18}$ but also psychiatric diseases such as depression, are correlated with an increased risk of falls.

Direct evidence for the association of ARWMC with falls is scarce but has been derived from several studies showing associations between ARWMC and gait and balance disturbances. ${ }^{78-21}$ Interruption of frontal lobe circuits and descending motor fibres has been discussed as the most probable cause of balance disturbances and falls in ARWMC. ${ }^{10}{ }^{19}$ These involve the prefrontal dorsolateral cortex ${ }^{22}$ but data correlating motor performance with the precise topography of ARWMC are scarce to date. ${ }^{21} 23$

In the present study, the association of ARWMC with balance disturbances and the rate of falls in a large cohort of elderly non-disabled individuals were analysed using the cross sectional data of the Leukoaraiosis and Disability in the Elderly (LADIS) study. The purpose of this paper was to define the detailed anatomical distribution of ARWMC to ascertain the structural and functional relationship hypothesised.

\section{METHODS}

\section{Sample and protocol}

Data were derived from the LADIS study. In this multinational study, 11 European centres collaborate with the purpose of assessing the role of ARWMC as an independent predictor of transition to disability in the non-disabled elderly. ${ }^{6}$

In total, 639 elderly individuals were enrolled in a hospital based setting, presenting with no or mild disability in the instrumental activities of daily living, defined as no impairment at all or only 1 item compromised in the instrumental activities of daily living scale. ${ }^{24}$ At baseline, MRI studies following a standard protocol ${ }^{6}$ were performed 


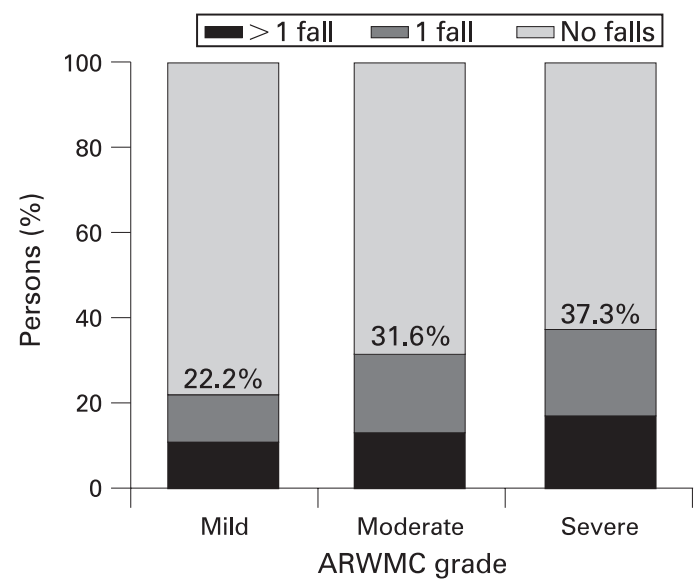

Figure 1 Rate of patients with a history of falls in the year prior to study inclusion in the three age related white matter changes (ARWMC) severity groups (mild, moderate, severe), according to the Fazekas scale.

and the degree of ARWMC severity was categorised into three groups (mild, moderate and severe) using the visual scale of Fazekas. ${ }^{25}$ Inclusion and exclusion criteria have been described in detail previously. ${ }^{6}$

At baseline and during the yearly follow-up, an extensive set of clinical and functional tests was performed. This included a structured and comprehensive questionnaire to assess vascular risk factors and comorbidity, as well as different global functioning, and cognitive, motor, psychiatric and quality of life measures, which were reviewed with the patient and a relative at baseline and every year during the 3 year follow-up period. Both the occurrence and frequency of falls were documented as separate items in this structured questionnaire.

Table 1 Independent effect of ARWMC, comorbidities and other factors on falls

\begin{tabular}{|c|c|c|c|}
\hline \multirow[b]{2}{*}{ Factor } & Univariate & Multivariate* & \multirow[b]{2}{*}{ p Value $\uparrow$} \\
\hline & OR $(95 \% \mathrm{Cl})$ & OR $(95 \% \mathrm{Cl})$ & \\
\hline ARWMC (Fazekas scale $>1$ ) & $1.82(1.28-2.60)$ & $1.60(1.07-2.41)$ & 0.024 \\
\hline Lacunes $(\geqslant n=1)$ & $1.25(0.88-1.76)$ & $1.14(0.76-1.69)$ & 0.533 \\
\hline Complaints of gait disturbance & $3.17(2.22-4.53)$ & $2.82(1.83-4.35)$ & $<0.001$ \\
\hline Female gender & $1.81(1.27-2.58)$ & $1.74(1.14-2.65)$ & 0.011 \\
\hline Age $\geqslant 75$ years & $1.35(0.96-1.91)$ & $1.13(0.76-1.68)$ & 0.551 \\
\hline Memory impairment & $1.72(1.19-2.48)$ & $1.22(0.79-1.88)$ & 0.376 \\
\hline Syncopal events & $1.78(1.15-2.74)$ & $1.57(0.96-2.57)$ & 0.072 \\
\hline Vertigo & $1.64(1.10-2.44)$ & $1.01(0.64-1.60)$ & 0.971 \\
\hline Depression & $1.38(0.95-2.00)$ & $0.94(0.61-1.45)$ & 0.764 \\
\hline Stroke & $0.97(0.66-1.42)$ & $0.82(0.52-1.29)$ & 0.387 \\
\hline Cardiac arrhythmias & $1.07(0.69-1.65)$ & $0.91(0.55-1.50)$ & 0.721 \\
\hline Hypertension & $1.18(0.81-1.73)$ & $1.22(0.79-1.90)$ & 0.375 \\
\hline Diabetes mellitus & $1.04(0.64-1.69)$ & $0.93(0.53-1.61)$ & 0.789 \\
\hline Osteoarthritis & $1.17(0.80-1.72)$ & $0.80(0.51-1.24)$ & 0.312 \\
\hline Hearing loss & $1.09(0.77-1.53)$ & $1.04(0.69-1.56)$ & 0.862 \\
\hline Visual loss & $1.50(0.97-2.31)$ & $0.98(0.59-1.62)$ & 0.942 \\
\hline Physical activity & $0.48(0.34-0.69)$ & $0.60(0.39-0.93)$ & 0.023 \\
\hline
\end{tabular}

*Binary logistic regression model (stepwise selection of variables, model included the variables: age $\geqslant 75$ years, sex, ARWMC severity, lacunes, hypertension, diabetes mellitus, syncopal events, cardiac arrhythmias, peripheral vascular disease, osteoarthrosis, stroke, transient ischaemic attack; complaints of gait disturbance, memory impairment, depression, vertigo, hearing loss, visual loss and physical activity; centre origin was included as a covariable).

tp values refer only to the multivariate analysis.

ARWMC, age related white matter changes.
To assess physical performance and postural control, a previously described test battery, ${ }^{9}$ including the Short Physical Performance Battery $(\mathrm{SPPB})^{26}$ and the single leg stance time as a simple test for balance ability ${ }^{7}$ was used. This test battery comprised timed clinical tests assessing locomotion (walking speed), and balance and postural control (single leg stance time, tandem stance, chair stands), all of which are supposedly controlled by cortico-subcortical functional loops.

\section{MRI scans and visual ratings}

All persons underwent cerebral MRI following a standard protocol. Scans were evaluated centrally at the Image Analysis Centre of the Vrije Universiteit Medical Centre, Amsterdam, The Netherlands. ${ }^{27}$ Visual ratings of ARWMC were carried out at this centre by a single rater who was blinded to the clinical details. Apart from assessment of the degree of global ARWMC and severity according to the Fazekas scale, the anatomical distribution of ARWMC was described using the semiquantitative Scheltens scale. ${ }^{28}$ In this scale, the severity of hyperintensities in the different anatomical areas of the brain is scored separately, including three periventricular regions, four areas of deep white matter, five areas of the basal ganglia and four different infratentorial regions.

The number of lacunes was counted in each of the same anatomical regions but not subdivided by side of brain. ${ }^{27}$

During the evaluation of the follow-up MRI scans, baseline MRI rating was corrected in 22 scans. This correction was necessary because of a mistake in the data processing, not because they were misclassified. The correction proved not to affect the main results of the baseline analyses but resulted in small differences in some data reported in the present paper compared with those reported in previous publications.

\section{Statistical analysis}

A non-parametric Kruskal-Wallis test was conducted to compare the rate of falls between the different ARWMC severity groups. Furthermore, non-parametric Mann-Whitney $\mathrm{U}$ tests were used to compare the means of the single leg stance time and the SPPB subscore "standscore" in patients with and without falls and in the different groups of ARWMC severity, respectively. To determine differences between the mean single scores of the Scheltens scale in patients with and without falls, univariate non-parametric Mann-Whitney $\mathrm{U}$ tests and a multivariate binary logistic regression model were used.

To describe variations in different factors depending on the history of falls, univariate analyses were performed using odds ratios (ORs) with $95 \%$ confidence intervals (CIs). Subsequently a binary logistic regression model was carried out to test independently the effect of factors associated with falls in order to obtain adjusted ORs. Finally, a binary logistic regression model was used to determine the independent association of severe hyperintensities in different brain regions according to the Scheltens scale with a diminished balance ability, ascertained by the single leg stance time.

All statistical analyses were calculated using SPSS for Windows, V.15 (SPSS Inc, Chicago, Illinois, USA).

\section{RESULTS}

In total, 639 individuals with a mean age of 74.1 (5.0) years were included in the study (288 men and 351 women). According to the Fazekas scale, 284 people (44.4\%) had mild, $197(30.8 \%)$ moderate and $158(24.7 \%)$ severe ARWMC at baseline. 


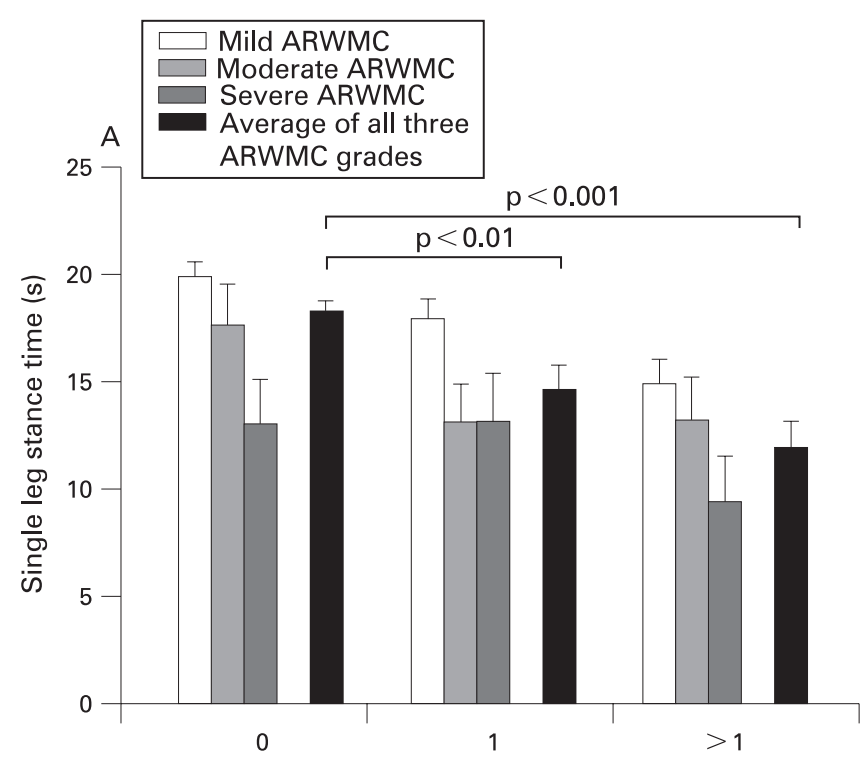

Falls in the year prior to study inclusion

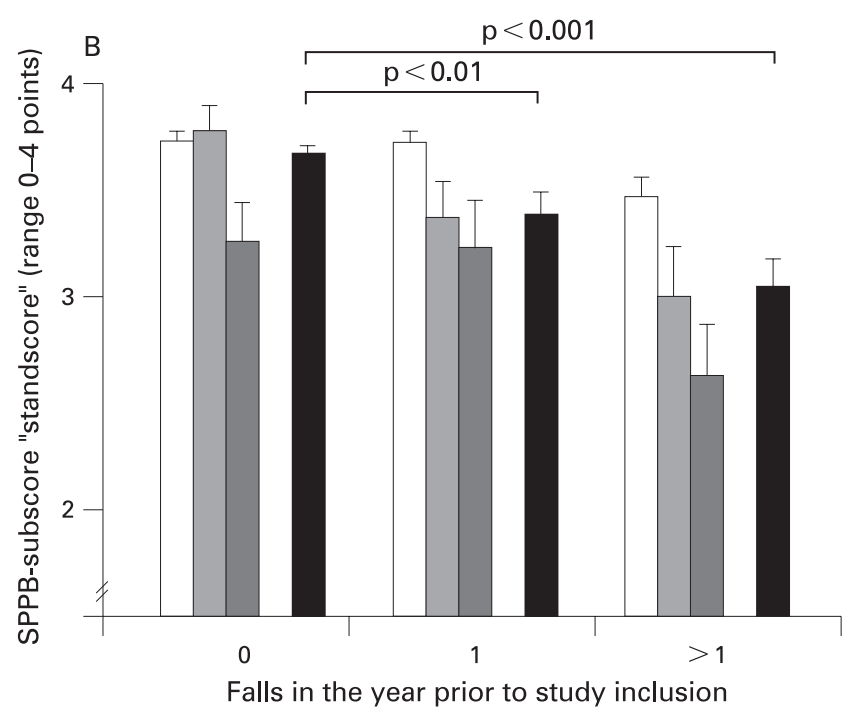

Figure 2 Mean single leg stance time $(A)$ and the standing balance subscore of the Short Physical Performance Battery (SPPB) (B), dependent on the rate of falls in the year prior to study inclusion. Values are mean (SEM) for the different severities of age related white matter changes (ARWMC) according to the Fazekas scale, separately for the three groups (mild, moderate and severe), and the averaged values of all three degrees of ARWMC severity.

At first, a statistically significant association of global ARWMC with a positive history of falls in the year prior to study inclusion (fig 1) was found. The rate of falls was $22.2 \%$ in the mild, $31.6 \%$ in the moderate and $37.3 \%$ in the severe ARWMC group $(p=0.002)$.

Using a binary logistic regression model to study the impact of comorbidity (table 1), apart from moderate to severe ARWMC, complaints of gait disturbance and female gender were identified as independent factors for an increased rate of falls in the year prior to study inclusion. The association of memory impairment, syncopal events and vertigo with falls found in univariate analysis was no longer significant in the multivariate binary logistic regression model. Detection of lacunes on MRI as the second main type of vascular pathology seen in the white matter was not associated with an increased rate of falls. Physical activity was associated with a significant lower rate of falls (OR 0.60 (95\% CI 0.39 to 0.93); $p=0.023$ ).

In fig 2 , the single leg stance time (fig $2 \mathrm{~A}$ ) and the standing balance subscore of the SPPB (fig 2B) as simple tests for balance ability are plotted against the rate of falls in the year prior to study inclusion. Compared with those without a history of falls (mean 18.2 (SEM 0.5) s), the mean single leg stance time was significantly reduced both in individuals with a history of multiple falls $(11.9(1.2) \mathrm{s} ; \mathrm{p}<0.001)$ and in those with a single fall (14.6 (1.1) s; $\mathrm{p}<0.01$ ) in the previous year (fig 2A). Furthermore, within each of these three groups, the single leg stance time was significantly correlated with the severity of ARWMC ( $p<0.05$ in the Kruskal-Wallis test, respectively).

Likewise, the standing balance subscore of the SPPB (fig 2B) was significantly reduced in individuals with a history of multiple falls (3.05 (0.13); $<<0.001)$ and a single fall (3.38 (0.11); $\mathrm{p}<0.01)$, compared with those without falls $(3.67(0.03))$ in the previous year.

Analysing the detailed anatomical distribution of ARWMC, as assessed by the Scheltens scale (table 2), falls were associated with increased scores in the ratings of periventricular ARWMC (frontal caps, occipital caps and lateral ventricle bands) as well as frontal and parietal deep ARWMC. In contrast, falls did not show a significant correlation with temporal and occipital deep ARWMC, basal ganglia lesions or infratentorial foci of ARWMC in the present cohort. In a multivariate binary logistic regression model, only periventricular $(p=0.006)$ and frontal deep ARWMC $(p=0.033)$ remained significantly associated with falls.

In table 3, the independent effect of the anatomical distribution of ARWMC on balance ability, as reflected by single leg stance time, using a binary logistic regression model, is presented. Similar to the results observed for the rate of falls, a significant association of severe frontal deep ARWMC ( $p=0.003)$ and a trend for severe hyperintensities located in the internal capsule $(p=0.057)$ with a diminished balance ability, determined by a reduced single leg stance time under $15 \mathrm{~s}$, was demonstrated. However, temporal and occipital deep ARWMC, other basal ganglia lesions and infratentorial ARWMC were not associated with significant balance disturbances.

\section{DISCUSSION}

Further to the previously reported association of ARWMC with global motor impairment and gait disturbances, ${ }^{9}$ this study has demonstrated that falls are significantly associated with the global severity of ARWMC in a cross section of a large cohort of 639 elderly persons. Furthermore, the rate of falls and the severity of ARWMC were significantly associated with balance disturbances.

Apart from other sources of falls, such as orthopaedic diseases, visual impairment or peripheral neuropathies, gait disturbances are an important determinant of falls. However, we found that ARWMC represent a further independent risk factor for falls. Thus we postulate that comparable with other movement disorders such as Parkinson's disease, ${ }^{29}$ impairment of postural control, which is not necessarily closely related to the severity of gait dysfunction, should be the most important cause of falls in patients with ARWMC. Clinically, early identification of patients with ARWMC at risk of falls using simple clinical tests, such as the single leg stance time, might be of relevance.

Using a novel approach in a large study, detailed anatomical studies of ARWMC have confirmed the hypothesis that falls and balance disturbances are associated primarily with frontal 
Table 2 Mean single scores and subscores of the Scheltens scale in patients with and without falls in the year prior to study inclusion

\begin{tabular}{|c|c|c|c|c|}
\hline \multirow[b]{2}{*}{ Scheltens scale item } & \multicolumn{2}{|c|}{ Falls in the year prior to study inclusion } & \multirow{2}{*}{$\begin{array}{l}\text { p Value* } \\
\text { Univariate }\end{array}$} & \multirow{2}{*}{$\begin{array}{l}\text { p Value } \dagger \\
\text { Multivariate }\end{array}$} \\
\hline & No & Yes & & \\
\hline PVH frontal caps & $1.35(1.30-1.41)$ & 1.52 (1.44-1.59) & 0.004 & \\
\hline PVH occipital caps & $1.47(1.43-1.53)$ & 1.60 (1.53-1.67) & 0.016 & \\
\hline PVH lateral bands & $1.23(1.18-1.28)$ & $1.40(1.33-1.48)$ & 0.001 & \\
\hline PVH subscore & $4.06(3.94-4.17)$ & 4.52 (4.33-4.70 & $<0.001$ & 0.006 \\
\hline WMH frontal & $3.77(3.62-3.94)$ & $4.30(4.07-4,52)$ & $<0.001$ & 0.033 \\
\hline WMH parietal & $3.54(3.36-3.73)$ & $3.93(3.64-4.23)$ & 0.009 & 0.122 \\
\hline WMH occipital & $0.34(0.25-0.43)$ & $0.47(0.29-0.66)$ & 0.740 & 0.856 \\
\hline WMH temporal & 1.73 (1.57-1.89) & 1.99 (1.72-2.27) & 0.184 & 0.675 \\
\hline WMH subscore & $9.39(8.92-9.85)$ & $10.67(9.94-11.41)$ & 0.004 & \\
\hline BG caudate nucleus & $0.06(0.02-0.09)$ & $0.07(0.01-0.13)$ & 0.922 & 0.870 \\
\hline BG putamen & $0.40(0.31-0.49)$ & $0.40(0.25-0.54)$ & 0.899 & 0.246 \\
\hline BG globus pallidus & $0.18(0.12-0.24)$ & $0.19(0.10-0.28)$ & 0.886 & 0.402 \\
\hline BG thalamus & $0.37(0.28-0.46)$ & $0.49(0.34-0.65)$ & 0.190 & 0.851 \\
\hline BG internal capsule & $2.20(2.01-2.38)$ & $2.52(2.21-2.83)$ & 0.079 & 0.512 \\
\hline BG subscore & $3.21(2.91-3.51)$ & $3.68(3.17-4.19)$ & 0.129 & \\
\hline ITF cerebellar & $0.09(0.05-0.14)$ & $0.18(0.08-0.28)$ & 0.576 & 0.312 \\
\hline ITF mesencephal & $0.10(0.04-0.15)$ & $0.28(0.14-0.42)$ & 0.214 & 0.069 \\
\hline ITF pontine & $0.60(0.49-0.71)$ & $0.88(0.65-1.10)$ & 0.182 & 0.525 \\
\hline ITF medullar & $0.02(0.00-0.04)$ & 0.00 & 0.896 & 0.999 \\
\hline ITF subscore & $0.81(0.65-0.96)$ & $1.33(1.00-1.66)$ & 0.066 & \\
\hline Total Scheltens Score & 17.46 (16.65-18.27) & $20.20(18.82-21.57)$ & 0.001 & \\
\hline
\end{tabular}

\footnotetext{
Values are means $(95 \% \mathrm{Cl})$.

*Univariate Mann-Whitney U test.

$\uparrow$ Multivariate binary logistic regression with a history of falls as the dependent variable and grouped PVH subscore as well as the different WMH, BG and ITF single item scores as independent variables (range 0-6 points for each score).

\$Total score, range $0-84$ points.

BG, basal ganglia hyperintensities, range 0-6 points for every item and 0-30 points for grouped subscore; ITF, infratentorial foci of hyperintensities, range 0-6 points for every item and 0-24 points for grouped subscore; $\mathrm{PVH}$, periventricular hyperintensities, range $0-2$ points for every item and 0-6 points for grouped subscore; WMH, deep white matter hyperintensities, range 0-6 points for every item and 0-24 points for grouped subscore.
}

deep and periventricular ARWMC. These lesions involve the cortico-subcortical circuit for motor control ${ }^{22}$ and result in disturbances of a widespread subcortical motor network as the most likely cause of balance disturbances and falls in ARWMC. ${ }^{719031}$ The observations are mainly in line with the results of a previous study comprising 28 elderly individuals with various degrees of impaired mobility. ${ }^{23}$

Different frontal lesions such as bilateral subdural haematomas, tumours or hydrocephalus are well known to be associated with gait and balance disturbances. ${ }^{32}$ Periventricular as well as frontal and parietal deep ARWMC might interfere with long loop reflexes critical for gait and balance mediated by deep white matter sensory and motor tracts. ${ }^{30}$ In normal pressure hydrocephalus, characterised by a "frontal" gait disorder similar to that in ARWMC, gait dysfunction and balance disturbances have been attributed to interruptions of corticocortical fibres projecting to the frontal cortex or lesions of frontocerebellar pathways. ${ }^{32}$ Lesions in the frontal deep white matter and lateral to the frontal horns of the ventricles may also affect the frontooccipital fasciculus and the more laterally located superior longitudinal fasciculus ${ }^{33}$ that are involved in sensorimotor integration and postural control. Another traditional hypothesis for the cause of gait disturbances in hydrocephalus is the effect on the descending motor tracts related to lower extremity control, arising from medial cortical areas and passing close to the lateral ventricle before entering the internal capsule. ${ }^{34}$ However, according to the present results, a direct effect on the descending motor fibres in the areas of the internal capsule, pons and medulla oblongata seem to be of minor importance for balance disturbances and the risk of falls.

The exact pathophysiology and biology of how ARWMC affect frontal circuits is unclear. In a combined MRI and positron emission tomography study, Tullberg et al ${ }^{35}$ demonstrated that white matter lesions were associated with frontal hypometabolism, irrespective of their location. Given that the frontal and periventricular areas are the predominant locations for ARWMC, ${ }^{35}$ it could simply be that ARWMC in these regions are good estimates of global ARWMC magnitude. However, the results of the current study reveal that only frontal ARWMC are associated with balance disturbances despite considerable ARWMC scores even in other brain areas such as the periventricular and parietal white matter as well as the basal ganglia region. This clearly points to a specific role of frontal ARWMC in the occurrence of balance disturbances, most likely by direct interruption of frontal cortico-subcortical circuits responsible for motor control.

Apart from complaints of gait disturbance and female gender, no further independent factors or comorbidities associated with an increased rate of falls were found in the cohort. This is in contrast with previous studies which identified several risk 
Table 3 Independent association of severe hyperintensities in different brain regions with a diminished balance ability

\begin{tabular}{lll}
\hline Scheltens scale item & $\mathbf{O R}(\mathbf{9 5} \% \mathbf{C I})^{*}$ & $\mathbf{p}$ Value* \\
\hline PVH subscore & $1.06(0.70-1.63)$ & 0.777 \\
WMH frontal & $1.93(1.25-2.97)$ & 0.003 \\
WMH parietal & $0.88(0.57-1.35)$ & 0.547 \\
WMH occipital & $0.96(0.34-2.69)$ & 0.934 \\
WMH temporal & $1.24(0.68-2.24)$ & 0.480 \\
& & \\
BG putamen & $0.19(0.02-1.92)$ & 0.160 \\
BG thalamus & $1.24(0.25-6.06)$ & 0.791 \\
BG internal capsule & $1.57(0.99-2.51)$ & 0.057 \\
& & \\
ITF cerebellar & $1.36(0.10-18.02)$ & 0.816 \\
ITF mesencephal & $1.15(0.23-5.77)$ & 0.868 \\
ITF pontine & $1.30(0.56-3.67)$ & 0.620
\end{tabular}

Independent association of severe hyperintensities in different brain regions with a diminished balance ability.

*Binary logistic regression model with balance disturbances (defined as single leg stance time $<15 \mathrm{~s}$ ) as the dependent variable.

$\mathrm{BG}$, severe basal ganglia hyperintensities (subscore $>4$ points for every item; the items BG caudate nucleus and BG globus pallidus have been excluded from the model because of absence of scores $>4$ points in these regions); ITF, severe infratentorial foci of hyperintensities (subscore $>4$ points for every item, the item ITF medullar has been excluded from the model because of absence of scores $>4$ points in this region); $\mathrm{PVH}$, severe periventricular hyperintensities (grouped PVH subscore $>4$ points); WMH, severe deep white matter hyperintensities (subscore $>4$ points for every item).

factors for falls in elderly persons, in particular reduced vision, decreased hearing, cognitive impairment, depression and neuromuscular disorders. ${ }^{12} 153637$ A probable explanation for this discrepancy could be that individuals in the LADIS study were not disabled or only mildly disabled in activities of daily living, thus very few of those included persons had any of these risk factors for falls to a significant degree on enrolment.

Physical activity appeared to be clearly associated with a reduced rate of falls, supporting published data indicating that exercise, in particular when combined with balance training, could reduce the risk of falls ${ }^{38}{ }^{39}$ and mobility impairment. ${ }^{40}$ Assuming a possible beneficial effect of physical activity on falls and motor performance in ARWMC, this observation might have clinical implications. Nevertheless, the causal direction in this association remains unclear. It needs to be discussed more openly if the fear of falls and motor disturbances restrain patients from partaking in physical activity.

Among the strengths of the current study are the large sample size and the detailed MRI protocol with centralised analysis, which guaranteed reliability and accuracy of ARWMC scorings and identification of even small effects of ARWMC on motor performance. Furthermore, because of the relatively strict inclusion and exclusion criteria, the results of the present study are less biased by interacting effects of multiorgan disease in geriatric patients, unlike previous studies..$^{15} 3637$

Limitations of the present study include its cross sectional design as well as the retrospective assessment of falls based on patient history and an additional report of an informant. Furthermore, although the visual rating scales used here to assess ARWMC had the problem of non-linearity and possible ceiling effects, their equal validity in comparison with a complex volumetry in association with different clinical parameters was demonstrated previously in the LADIS study. ${ }^{41}$ In addition, the results of the multivariate statistical model estimating the influence of the anatomical distribution of ARWMC could be biased because of collinearities between the different Scheltens scale subscores, hampering a reliable evaluation of individual regression coefficients. Finally, a possible limitation for the generalisability of the results to a general population may be patient selection in a hospital based setting and the inclusion criterion of not being disabled. Individuals were required to have minor motor disturbances on enrolment and thus the extent of association between the severity of ARWMC and balance disturbances with falls may have been underestimated.

The longitudinal design of the LADIS study with a follow-up of 3 years, including cerebral MRI scans for quantification of the progression of ARWMC, will show if falls and disturbances in postural control are predictors of a transition to disability in elderly subjects with ARWMC. It will possibly also enable us to see which ARWMC, in terms of location and severity, will lead to new falls. Perspective functional MRI studies, including diffusion tensor magnetic resonance tractography, that allow detailed visualisation of different white matter fasciculi and pathways and its affect on ARWMC, ${ }^{42}$ will help to further specify the localisation of strategic white matter lesions and its correlation with motor disturbances.

In conclusion, for the first time using detailed anatomical studies of ARWMC in a large cohort of elderly non-disabled individuals, a significant association between falls and balance disturbances and primarily frontal deep and periventricular ARWMC was demonstrated. The present data confirm the hypothesis that these lesions interfere with the corticosubcortical circuit for motor control, resulting in disturbances of a widespread subcortical motor network, and thus are the most likely cause of balance disturbances and falls in ARWMC.

Acknowledgements: The LADIS Steering Committee is formed by Domenico Inzitari, MD (study coordinator), Timo Erkinjuntti, MD, PhD, Philip Scheltens, MD, PhD, Marieke Visser, MD, PhD, and Peter Langhorne, MD, BSC, PhD, FRCP who replaced in this role Kjell Asplund, MD, PhD beginning in 2005.

Funding: The LADIS Study is supported by the European Union within the Vth European Framework Programme "Quality of Life and Management of Living Resources" (1998-2002), contract No OLRT-2000-00446 as a concerted action. The sponsor played no role in the design, methods, subject recruitment, data collection, analysis or preparation of the paper.

\section{Competing interests: None.}

Ethics approval: The study was approved by the local ethics committee at the University of Heidelberg.

\section{REFERENCES}

1. Hachinski VC, Potter P, Merskey H. Leuko-araiosis. Arch Neurol 1987:44:21-3.

2. Pantoni L, Garcia JH. Pathogenesis of leukoaraiosis: a review. Stroke 1997;28:652-9

3. Longstreth WT, Maniolo TA, Arnold A, et al. Clinical correlates of white matter findings on cranial magnetic resonance imaging of 3301 elderly people. The Cardiovascular Health Study. Stroke 1996;27:1274-82.

4. Basile AM, Pantoni L, Praccuci G, et al. Age, hypertension, and lacunar stroke are the major determinants of the severity of age-related white matter changes Cerebrovasc Dis 2006:21:315-22.

5. Erkinjuntti T, Pantoni L, Scheltens P. Cooperation and networking on white-matterdisorders: The European Task-Force on Age-related White Matter Changes. Dement Geriatr Cogn Disord 1998;9(Suppl 1):44-5.

6. Pantoni L, Basile AM, Pracucci G, et al. Impact of age-related cerebral white matter changes on the transition to disability-the LADIS study: rationale, design and methodology. Neuroepidemiology 2005;24:51-62.

7. Guttmann CR, Benson R, Warfield SK, et al. White matter abnormalities in mobilityimpaired older persons. Neurology 2000;54:1277-83.

8. Baezner H, Oster M, Daffertshofer M, et al. Assessment of gait in subcortical vascular encephalopathy by computerized analysis: a cross-sectional and longitudinal study. J Neurol 2000;247:841-9.

9. Baezner H, Blahak C, Poggesi A, et al. Association of gait and balance disorders with age-related white matter changes: the LADIS study. Neurology 2008;70:935-42.

10. Baloh RW, Ying SH, Jacobson KM. A longitudinal study of gait and balance dysfunction in normal older people. Arch Neurol 2003;60:835-9.

11. Tell GS, Lefkowitz DS, Diehr $P$, et al. Relationship between balance and abnormalities in cerebral magnetic resonance imaging in older adults. Arch Neurol 1998;55:73-9.

12. Bloem BR, Steijns JAG, Smits-Engelsman BC. An update on falls. Curr Opin Neurol 2003;16:15-26. 
13. Rubenstein LZ, Powers CM, MacLean CH. Quality indicators for the management and prevention of falls and mobility problems in vulnerable elders. Ann Intern Med 2001;135:686-93.

14. Alexander BH, Rivara FP, Wolf ME. The cost and frequency of hospitalisation for fallrelated injuries in older adults. Am J Public Health 1992;82:1020-3.

15. Tinetti ME, Speechley M, Ginter SF. Risk factors for falls among elderly persons living in the community. N Engl J Med 1988;319:1701-7.

16. Maki BE. Gait changes in older adults: predictors of falls or indicators of fear. J Am Geriatr Soc 1997; 45:313-20.

17. Bloem BR, Grimbergen YAM, Cramer M, et al. Prospective assessment of falls in Parkinson's disease. J Neurol 2001;248:950-8.

18. Ebersbach G, Sojer M, Valldeoriola F, et al. Comparative analysis of gait in Parkinson's disease, cerebellar ataxia and subcortical arteriosclerotic encephalopathy. Brain 1999;122:1349-55.

19. Whitman GT, Tang T, Lin A, et al. A prospective study of cerebral white matter abnormalities in older people with gait dysfunction. Neurology 2001:57:990-4.

20. Kerber KA, Enrietto JA, Jacobson KM, et al. Disequilibrium in older people: a prospective study. Neurology 1998;51:574-80.

21. Starr JM, Leaper SA, Murray AD, et al. Brain white matter lesions detected by magnetic resonance imaging are associated with balance and gait speed. J Neurol Neurosurg Psychiatry 2003;74:94-8.

22. Alexander GE, DeLong MR, Strick PL. Parallel organization of functionally segregated circuits linking basal ganglia and cortex. Annu Rev Neurosci 1986;9:357-81.

23. Benson RR, Guttman CRG, Wie X, et al. Older people with impaired mobility have specific loci of periventricular abnormality on MRI. Neurology 2002;58:48-55.

24. Lawton MP, Brody EM. Assessment of older people: self-maintaining and instrumental activities of daily living. Gerontologist 1969;9:179-86.

25. Fazekas F, Chawluk JB, Alavi A, et al. MR signal abnormalities at $1.5 \mathrm{~T}$ in Alzheimer's dementia and normal aging. Am J Neuroradiol 1987;8:421-6.

26. Guralnik JMM, Ferrucci L, Simonsick EM, et al. Lower-extremity function in persons over the age of 70 years as a predictor of subsequent disability. $N$ Engl J Med 1995;332:556-61.

27. van der Flier WM, van Straaten ECW, Barkhof F, et al. Small vessel disease and general cognitive function in nondisabled elderly. Stroke 2005;36:2116-120.
28. Scheltens $\mathbf{P}$, Barkhof $F$, Leys $D$, et al. A semiquantitative rating scale for the assessment of signal hyperintensities on magnetic resonance imaging. J Neurol Sci 1993;114:7-12

29. Boonstra TA, van der Kooij $\mathrm{H}$, Munneke $\mathrm{M}$, et al. Gait disorders and balance disturbances in Parkinson's disease: clinical update and pathophysiology. Curr Opin Neurol 2008;21:461-71.

30. Masdeu JC, Wolfson L, Lantos G, et al. Brain white-matter changes in the elderly prone to falling. Arch Neurol 1989;46:1292-6.

31. Baezner $\mathbf{H}$, Hennerici M. From trepidant abasia to motor network failure - gait disorders as a consequence of subcortical vascular encephalopathy (SVE) - Review of historical and contemporary concepts. J Neurol Sci 2005;229-230:81-8.

32. Stolze H, Kuhtz-Buschbeck JP, Drücke $\mathbf{H}$, et al. Comparative analysis of the gait disorder of normal pressure hydrocephalus and Parkinson's disease. J Neurol Neurosurg Psychiatry 2001;70:289-97.

33. Curnes JT, Burger PC, Djang WT, et al. MR imaging of compact white matter pathways. Am J Neuroradiol 1988;9:1061-8.

34. Yakovlev PI. Paraplegias of hydrocephalics. Am J Ment Defic 1947:51:561-76.

35. Tullberg $\mathbf{M}$, Fletcher $\mathbf{E}$, DeCarli $\mathbf{C}$, et al. White matter lesions impair frontal lobe function regardless of their location. Neurology 2004;63:246-53.

36. Tinetti ME, Williams CS. Falls, injuries due to falls, and the risk of admission to a nursing home. N Engl J Med 1997;337:1279-84.

37. Voermans NC, Snijders AH, Schoon Y, et al. Why old people fall (and how to stop them). Pract Neurol 2007; 7:158-71.

38. Province MA, Hadley EC, Hornbrook MC, et al. The effects of exercise on falls in elderly patients. A preplanned meta-analysis of the FICSIT Trials. Frailty and Injuries: Cooperative Studies of Intervention Techniques. JAMA 1995;273:1341-7.

39. Day L, Fildes B, Gordon I, et al. Randomised factorial trial of falls prevention among older people living in their own homes. BMJ 2002;325:128-34.

40. Lang IA, Guralnik JM, Melzer D. Physical activity in middle-aged adults reduces risks of functional impairment independent of its effect on weigtht. J Am Geriatr Soc 2007:55:1836-41.

41. Gouw AA, Van der Flier WM, van Straaten EC, et al. Simple versus complex assessment of white matter hyperintensities in relation to physical performance and cognition: the LADIS study. J Neurol 2006;253:1189-96.

42. Catani M, Howard RJ, Pajevic S, et al. Virtual in vivo interactive dissection of white matter fasciculi in the human brain. Neuroimage 2002;17:77-94.

\section{Take advantage of BMJ Journals' remarkable catalogue of titles with Related Collections}

No busy professional has time to browse through all pertinent journals to find relevant articles, but with Related Collections you no longer have to. Follow the "Related Collections" link from any article and use the "Show Collections from other Journals" to expand your search across all BMJ Journals. Or simply follow the "Browse by topic" link on the home page. By setting up your own collections and receiving email alerts every time an article is added to your chosen area, you can build up your own significant body of knowledge. 


\section{JNNP}

\section{Deep frontal and periventricular age related white matter changes but not basal ganglia and infratentorial hyperintensities are associated with falls: cross sectional results from the LADIS study}

C Blahak, H Baezner, L Pantoni, et al.

J Neurol Neurosurg Psychiatry 2009 80: 608-613 originally published online February 9, 2009

doi: 10.1136/jnnp.2008.154633

Updated information and services can be found at:

http://jnnp.bmj.com/content/80/6/608.full.html

\section{These include:}

References This article cites 42 articles, 22 of which can be accessed free at: http://jnnp.bmj.com/content/80/6/608.full.html\#ref-list-1

Article cited in:

http://jnnp.bmj.com/content/80/6/608.full.html\#related-urls

Email alerting service

Receive free email alerts when new articles cite this article. Sign up in the box at the top right corner of the online article.

Notes

To request permissions go to:

http://group.bmj.com/group/rights-licensing/permissions

To order reprints go to:

http://journals.bmj.com/cgi/reprintform

To subscribe to BMJ go to:

http://group.bmj.com/subscribe/ 